\title{
INCLUSÃO DIGITAL DOS AGENTES TERCEIRIZADOS DO CAMPUS IV DA UFPB: um estudo de caso
}

\begin{abstract}
Resumo: O presente artigo tem por objetivo apresentar o resultado das ações desenvolvidas no projeto de extensão intitulado Inclusão digital de agentes terceirizados do Campus IV da UFPB, executado durante o ano de 2015. O estudo fundamenta-se na concepção de que uma verdadeira política de inclusão digital deverá se basear na capacitação para o acesso à informação, sendo classificado como descritivo, exploratório e de natureza quanti-qualitativa. As ações do projeto foram elaboradas e executadas com vistas a contribuir para o desenvolvimento social e profissional do público-alvo. As melhorias identificadas quanto ao seu desempenho sinalizam que tais ações configuram o primeiro passo para a inclusão digital e social dos participantes do projeto. Sugere-se, por fim, que o projeto tenha continuidade junto a este público, bem como que possa se estender aos seus familiares, conforme sugerido pelos próprios participantes, na avaliação final desta ação extensionista.
\end{abstract}

Palavras-chave: Inclusão digital. Inclusão social. Informação. Desenvolvimento. Agentes terceirizados.
Márcia Maria de M. Travassos Saeger Professora do Departamento de Ciências Sociais Aplicadas,

Universidade Federal da Paraíba, Brasil. marciatsaeger@yahoo.com.br

Júlio Afonso Sá de Pinho Neto Professor do Departamento de Comunicação,

Universidade Federal da Paraíba, Brasil. sadepinho@uol.com.br

Tabira de Souza Andrade Professora do Departamento de Ciências Sociais Aplicadas,

Universidade Federal da Paraíba, Brasil. tabirandrade@yahoo.com.br

\section{DIGITAL INCLUSION OF OUTSOURCED AGENTS OF CAMPUS IV OF THE UFPB: a case study}

\begin{abstract}
This article aims to present the results of the actions developed in the extension project titled Digital inclusion of outsourced agents of Campus IV of the UFPB, executed during the year 2015. The study is based on the conception that a true policy of digital inclusion should based on the training for access to information, classified as descriptive, exploratory and quantitative and qualitative nature. The actions of the project were elaborated and executed in order to contribute to the social and professional development of the target public. The identified improvements in their performance indicate that these actions are the first step towards the digital and social inclusion of project participants. It is suggested, finally, that the project should continue with this public, as well as that it may extend to their families, as suggested by the participants themselves, in the final evaluation of this extensionist action.
\end{abstract}

Keywords: Digital inclusion. Social inclusion. Information. Development. Outsourced agents. 


\section{INTRODUÇÃO}

A discussão sobre a inclusão digital vem ganhando espaço cada vez maior no âmbito da comunidade acadêmica e da sociedade em geral, em virtude da expansão tecnológica vivenciada nos últimos tempos e dos esforços dos governos, segmento privado e instituições do Terceiro Setor, no sentido de viabilizar o acesso às Tecnologias da Informação e Comunicação (TIC) à parcela da sociedade considerada excluída. Contudo, as ações que visam minimizar os efeitos da exclusão digital devem fundamentar-se em um processo educativo, de modo a capacitar os indivíduos para o uso das informações e da tecnologia, buscando o seu desenvolvimento e o exercício da cidadania.

O cenário atual é marcado pela formulação de políticas públicas de inclusão digital, com projetos desenvolvidos pelos governos federal, estaduais e municipais, com diferentes parcerias, mas ainda é patente a necessidade de um entendimento mais profundo sobre o que de fato constitui o objetivo das políticas de inclusão digital e sua relação indissociável com a inclusão social, indo além do mero acesso às tecnologias (CIMADEVILA; ZUCHETTI; BASSANI, 2013; AGUILAR, 2012; PINHO NETO, 2011; VECHIATO; VIDOTTI, 2010; MEDEIROS NETO; MIRANDA, 2009).

Dentre os vários agentes que desenvolvem projetos para a inclusão digital de parcelas da sociedade destituídas do acesso à informação por meio das TIC, encontra-se a Universidade, que pode atuar junto à comunidade através das ações de extensão. Ressalte-se que a ação extensionista deve ser pensada tanto para a comunidade externa à Universidade, como também para aqueles que colaboram com o seu pleno funcionamento, a exemplo dos profissionais que prestam serviços de limpeza, segurança, apoio administrativo e serviços de manutenção, os agentes terceirizados.

Nesse contexto, este trabalho objetiva apresentar o resultado das ações desenvolvidas no projeto de extensão intitulado Inclusão digital de agentes terceirizados do Campus $I V d a$ $U F P B$, cujas atividades foram planejadas com o intuito de contribuir para o desenvolvimento social e profissional desse público-alvo. O projeto foi elaborado tendo como sustentação teórica a contribuição trazida pela Ciência da Informação e sua vertente social, posto que o acesso e uso da informação, mediado pelo uso das TIC, deverá promover o desenvolvimento pessoal e social dos indivíduos, sendo, pois, impossível conceber este como um direito restrito a apenas uma parcela da sociedade. 


\section{AS CONTRIBUIÇÕES DA CIÊNCIA DA INFORMAÇÃO PARA A ELABORAÇÃO DE PROJETOS DE INCLUSÃO DIGITAL}

Os avanços tecnológicos têm contribuído para que o acesso à informação se dê de maneira cada dia mais rápida, superando barreiras de tempo e espaço. As Tecnologias de Informação e Comunicação (TIC) influenciam as relações entre as pessoas e até mesmo suas ações e pensamentos, interferindo no contexto social e no trabalho dos indivíduos.

Seu desenvolvimento, a partir dos anos 1990, trouxe a perspectiva de melhoria em relação ao acesso à informação e ao conhecimento, propiciando assim uma sociedade mais democrática. Nos dias atuais, é claro o entendimento de que o exercício da cidadania se torna algo intimamente ligado ao acesso e domínio das TIC, fundados na reflexão e na crítica (MASSENSINI, 2011).

Essa explosão das tecnologias revela a necessidade de um olhar sobre o contexto social no qual esse processo ocorre. O desenvolvimento das TIC trouxe a perspectiva de melhoria social, a partir da inserção dos indivíduos em um ambiente de rápida disseminação de informações, mas também fez surgir uma nova divisão social, postulada em função das desigualdades quanto ao acesso a estas tecnologias. Sobre esse aspecto, Saraiva, Martins e Pieranti (2008, p. 111) consideram a ocorrência do apartheid digital, pois "uma parcela elitizada da população utiliza os mais sofisticados recursos, enquanto muitos brasileiros jamais utilizaram um microcomputador".

Tal situação motiva a criação de políticas públicas que objetivam minimizar essas desigualdades, a partir da inclusão digital, que, na visão de Martini (2005) e Pinho Neto (2012), se traduz como um conjunto de políticas que viabilizem meios para que o acesso às tecnologias contribua para o desenvolvimento social e profissional dos sujeitos, sendo consequência da inclusão social. Pinheiro (2007, p. 3) considera que a inclusão digital ocorre de fato "quando o indivíduo deixa de exercer o papel passivo de consumidor de informações, bens e serviços e passa a atuar como produtor de conhecimentos, bens e serviços".

Todavia, infelizmente resultados de pesquisas recentes sobre a efetivação de políticas públicas de inclusão digital de segmentos excluídos da sociedade, traduzidas na execução de projetos propostos para este fim e desenvolvidos por todo o Brasil, apontam para a ausência de políticas que atendam de maneira fidedigna ao objetivo da inclusão digital, posto que um número significativo destes projetos acaba por subsidiar apenas o acesso às tecnologias, sem o 
prévio planejamento das necessidades do público-alvo e sem a devida capacitação para o uso das tecnologias para a cidadania.

O simples acesso às tecnologias não garante que o objetivo da inclusão digital seja atendido, sendo necessário, conforme ressaltam Aun (2007), Freire (2010) e Pinho Neto (2012), viabilizar meios para que esse acesso ocorra em um ambiente que estimule a reflexão e a crítica, garantindo a produção de conhecimento, por meio de informações relevantes e eficientes.

Ao considerar os meios para que ocorra verdadeiramente uma política de inclusão digital, faz-se mister refletir sobre o processo que irá nortear o acesso e uso das informações, bem como a mediação entre os usuários da informação e as tecnologias, contexto no qual se insere a Ciência da Informação (CI), definida por Borko (1968, p. 3, tradução nossa) como:

\footnotetext{
A disciplina que investiga as propriedades e o comportamento da informação, as forças que regem o fluxo de informação e os meios de processamento de informação para melhor acessibilidade e usabilidade. Ela está preocupada com o corpo de conhecimento relacionado com a origem, coleta, organização, armazenamento, recuperação, interpretação, transmissão, transformação e utilização da informação.
}

A informação, que se constitui no objeto de estudo da CI, é um fenômeno de natureza social, devendo ser observada a relação entre o indivíduo e o contexto sociocultural e histórico no qual ele está inserido, posto que a informação não é construída apenas a partir de um indivíduo, mas sim, de um coletivo. A construção da informação se dá por meio das interações dos indivíduos e deve impulsionar o seu desenvolvimento (CAPURRO, 2003).

Desta forma, considerando as concepções oriundas do paradigma social da CI, apoiado na ideia de que a informação deverá subsidiar o desenvolvimento individual e social, além de um cenário marcado pelo uso das tecnologias para o acesso à informação, o profissional da informação se insere no contexto da inclusão digital como um elemento fundamental, por auxiliar, segundo Bates (1999), no entendimento das necessidades e atitudes para a utilização da informação, atuando como mediador entre usuário e tecnologias.

Ressalte-se que uma verdadeira política de inclusão digital deverá se basear na capacitação para o acesso à informação, tornando os indivíduos competentes em informação. Sobre esse aspecto, Silva et al. (2005) ressaltam que a inclusão digital irá muito além do acesso às TIC, posto que os sujeitos deverão acessar informações por meio das tecnologias, 
mas também compreendê-las e saber utilizá-las para a melhoria da sua qualidade de vida e para poder intervir na sociedade.

Destarte, considerando que a inclusão digital fundamenta-se no tripé TIC, renda e educação (PINHEIRO, 2007), propondo o acesso, o uso e o compartilhamento das informações com vistas ao desenvolvimento social, o arcabouço teórico da Ciência da Informação fornece o subsídio necessário para a elaboração de projetos de inclusão digital, com base na competência informacional e no processo de mediação das ações inclusivas, a fim de que tais ações não se limitem a fornecer à parcela da sociedade considerada excluída digitalmente apenas o uso de computadores e internet.

\section{PROCEDIMENTOS METODOLÓGICOS}

Esta pesquisa compreende um estudo exploratório e descritivo, envolvendo levantamento bibliográfico e documental, com abordagem quantiqualitativa. Como objetivo, buscou apresentar as ações desenvolvidas no projeto de extensão Inclusão digital de agentes terceirizados do campus $I V$ da UFPB.

O referido projeto, aprovado no Edital PROBEX 2015 da UFPB, foi executado entre maio e dezembro de 2015, com aulas realizadas no laboratório de informática de uma das unidades do campus. O projeto teve como objetivo geral contribuir para o desenvolvimento social e profissional de agentes terceirizados que prestam serviços no campus IV da UFPB, oferecendo um curso de informática básica, com vistas à inclusão digital deste público.

Foram elencados como objetivos específicos do projeto: a) desenvolver um ciclo de formação sobre inclusão digital e fomentar a discussão e reflexão crítica sobre o uso das TIC e como elas poderão auxiliar no desenvolvimento deste grupo e da sociedade; b) oferecer um curso de informática básica, com carga horária de 40 horas e conteúdos voltados para o uso do computador, programas de edição de textos e slides e internet; c) promover a interação dos envolvidos no projeto por meio de uma rede social, de modo a combinar os conhecimentos compartilhados durante o curso e a utilização da internet como espaço de colaboração e socialização; d) aproximar alunos dos cursos do campus IV da UFPB da realidade específica que cerca a inclusão digital; e) contribuir para que um saber acadêmico mais adaptado à realidade das comunidades excluídas social e digitalmente seja consolidado. 
Os dados foram coletados a partir da aplicação de um instrumento de pesquisa com perguntas objetivas para avaliar os níveis de inclusão digital do público-alvo, de entrevistas com os participantes do projeto e da análise dos relatórios das atividades desenvolvidas ao longo do projeto.

O instrumento de pesquisa aplicado junto ao público-alvo foi adaptado da pesquisa desenvolvida por Bolzan et al. (2013), dividido em duas partes. A primeira, constituída de 14 afirmações referentes ao uso de programas do computador e sua configuração, teve como pontuação máxima possível 29,2 pontos, computados os pesos de cada afirmação. A segunda parte conteve 19 afirmações referentes ao uso da internet, abrangendo a busca de informações, utilização de serviços, mecanismos de interação, uso do correio eletrônico e participação em redes sociais, sendo a pontuação máxima possível de 45,6 pontos.

As respostas às afirmações deveriam ser assinaladas a partir de uma escala do tipo Likert, com os critérios nunca, raramente, frequentemente ou sempre e cada afirmação possui um peso específico, sendo o menor 0,2 e o maior 4. A pontuação máxima permitida ao questionário após a adaptação foi de 74,8 pontos, o que corresponderia a $100 \%$.

Ressalte-se que o instrumento original de coleta de dados que embasou esta pesquisa contém também afirmações sobre programação de computadores e configuração de redes e sistemas operacionais, contudo, tais afirmações não foram incluídas nessa pesquisa por não figurarem no programa proposto para o curso de informática.

A população da pesquisa foi correspondente aos agentes terceirizados que participaram do curso até a sua conclusão. Desta feita, inicialmente, foram inscritos 15 agentes terceirizados. Quando do início das aulas, estiveram presentes 13 agentes, porém, ao longo do curso, 4 não puderam continuar frequentando as aulas, em função da incompatibilidade com as escalas de trabalho e não liberação pela empresa responsável pelos serviços terceirizados. Sendo assim, foram computados apenas os resultados dos 9 agentes que permaneceram até o final do projeto e que receberam os seus certificados.

\section{APRESENTAÇÃO DOS RESULTADOS}

As ações desenvolvidas no projeto investigado tiveram início em maio de 2015, com duas rodadas de discussão sobre inclusão digital e sobre o uso das TIC e como elas podem auxiliar no desenvolvimento da sociedade, tendo como participantes os 6 alunos 
extensionistas do projeto. Esta etapa foi necessária para garantir o nivelamento da equipe antes da execução das atividades junto ao público-alvo.

A segunda etapa do projeto consistiu na aplicação do instrumento de pesquisa descrito nos procedimentos metodológicos, com os agentes terceirizados inscritos no projeto. $\mathrm{O}$ objetivo foi identificar o nível de inclusão digital dos participantes do projeto antes do curso e tomar os resultados obtidos como base para as eventuais adequações no planejamento das aulas, considerando as principais dificuldades apontadas pelo instrumento de pesquisa. Foi considerado como nível de inclusão digital ideal ou desejado o nível máximo de pontos obtidos por etapa e a partir desse valor numérico foi verificada a dispersão entre o desejado e o percebido, com base nos resultados obtidos com a pesquisa.

Antes do curso, considerando os conhecimentos que os participantes já possuíam sobre o uso de programas do computador e sua configuração, verificou-se que a pontuação média percebida na primeira etapa foi de 9,3 pontos, sendo 7,2 a menor pontuação e 15 a maior, ressaltando-se, mais uma vez, que a pontuação máxima possível nessa etapa é de 29,2 pontos. Em relação à segunda etapa do instrumento de pesquisa, correspondente ao uso da internet, abrangendo a busca de informações, utilização de serviços, mecanismos de interação, uso do correio eletrônico e participação em redes sociais, foi percebida uma média de 18,6 pontos, sendo 11,9 a menor pontuação e 23 a maior. Esta segunda etapa tem uma pontuação máxima possível de 45,6 pontos. A média geral percebida antes do curso foi de 27,9 pontos, sendo 20,8 a menor e 38 a maior pontuação, e o total desejado na pesquisa é de 74,8 pontos.

Os seguintes aspectos apresentaram maior índice de dificuldade entre os participantes: organizar arquivos em pastas e diretórios; resolver problemas de configurações de teclado; redigir e formatar textos em programas de edição de textos; preparar e formatar apresentações de slides; configurar e atualizar o computador com proteção contra vírus; consultar fóruns e comunidades na internet para solucionar problemas; utilizar recursos de anexar arquivos em correio eletrônico; criar e atualizar páginas pessoais na internet (blogs). Com base nestes resultados, algumas aulas do curso de informática básica foram readequadas, a fim de que tais conteúdos fossem trabalhados por mais tempo junto aos participantes do projeto.

Ao final do curso, que teve carga horária de 40 horas, foram realizadas entrevistas com os participantes e foi aplicado mais uma vez o instrumento de pesquisa, com o intuito de verificar qualitativa e quantitativamente os resultados do projeto. 
Em termos quantitativos, percebeu-se que o nível de inclusão digital dos participantes teve aumento percentual de 49,8 pontos em relação à média antes do curso, todavia, ainda permaneceu com considerável dispersão em relação ao nível desejado. Os resultados por etapa antes e depois da realização do curso podem ser verificados no gráfico 1.

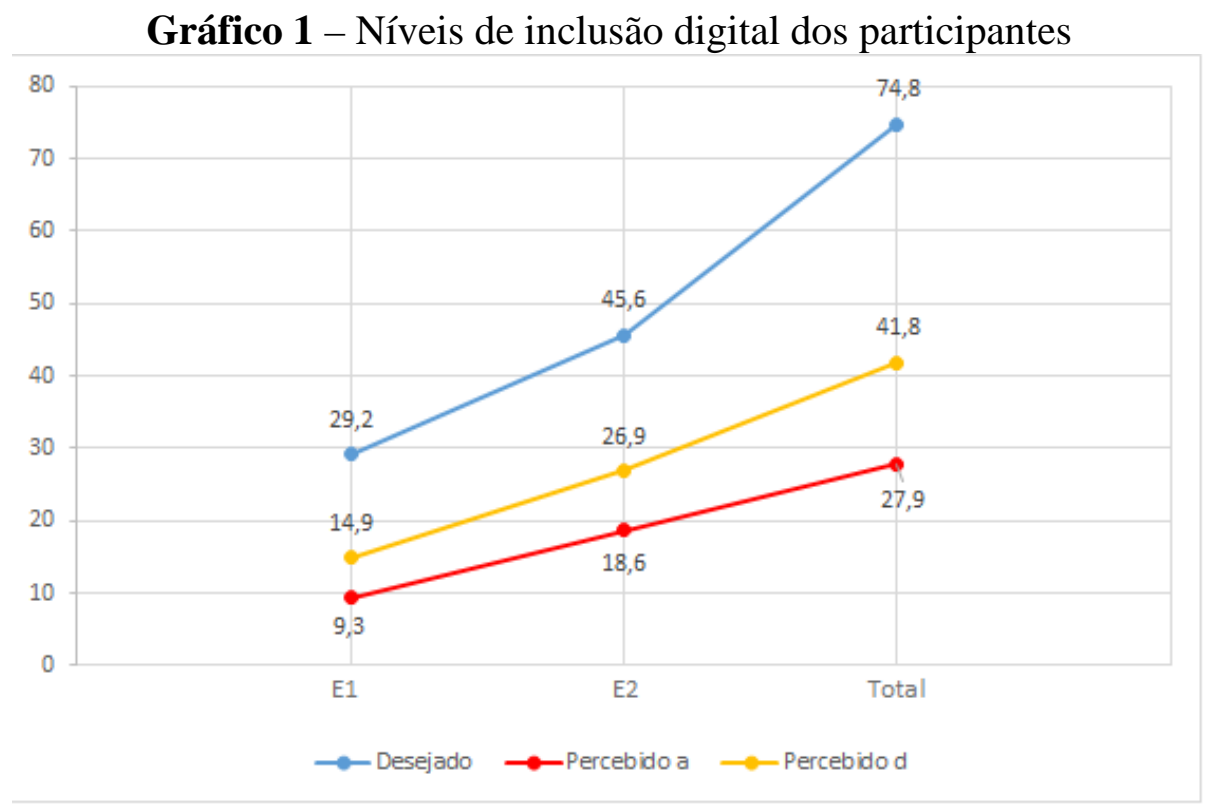

Fonte: Dados da pesquisa (2016).

O desempenho dos participantes foi melhor quanto aos conteúdos abordados na segunda etapa do projeto, notadamente no que concerne ao uso da internet, busca de informações e uso do correio eletrônico. Durante as entrevistas, alguns participantes afirmaram que a etapa das aulas relativas à internet foi mais fácil para o aprendizado, pois, mesmo não possuindo computadores em casa, os conteúdos trabalhados poderiam ser revistos nos smartphones ou tablets, o que não era possível em relação aos conteúdos para configuração do computador, edição de textos e apresentação de slides.

Dentre as atividades de edição e formatação de textos, os participantes redigiram seus currículos e cartas de apresentação. Todos os alunos salvaram tais documentos em versão eletrônica, contudo, apenas 3 afirmaram ter segurança para atualizar os currículos sem o auxílio dos monitores do curso. A criação de apresentações de slides foi apontada pela maioria dos participantes, ao final do curso, como uma atividade com pouco nível de dificuldade. 
Quanto à busca de informações na internet, todos os participantes do curso afirmaram não ter dificuldades em encontrar sites de pesquisas, sendo o Google e o YouTube mencionados como as principais fontes de pesquisa, seja para a busca de novas informações ou para solucionar problemas. Alguns participantes relataram que após o curso passaram a buscar vídeos no YouTube, citando como exemplos aprender a configurar celulares e até mesmo para aprender sobre montagem de motos. Os serviços de compras pela internet continuam sendo pouco utilizados, sendo a falta de confiança em alguns sites a principal razão apontada.

O uso do correio eletrônico passou a ser mais frequente entre eles, com estímulo ao envio periódico de mensagens com anexos. Contudo, nem todos os participantes afirmaram se sentir seguros para anexar arquivos sem o auxílio dos monitores do curso. Quanto à criação e atualização de páginas como $\log s$, foi unânime a opinião de que este foi um recurso novo apresentado no curso, e um dos participantes utilizou o blog criado para divulgar os produtos que comercializa, apontando esta atividade do curso como de grande utilidade pessoal.

No que concerne à utilização de redes sociais, todos os participantes possuem contas em pelo menos uma rede social, sendo o Facebook apontado como a principal rede para interação social. Apenas 1 participante do curso já utilizou a mencionada rede social para buscar contatos profissionais e 2 já utilizaram o recurso de compartilhar notícias através desta rede social antes do curso. Foi criada uma página do projeto no Facebook para a interação dos participantes, página esta que permaneceu ativa após o encerramento do curso.

Os participantes relataram também, nas entrevistas, as limitações que perceberam no curso, a saber: a carga horária reduzida, pois gostariam que o curso tivesse carga superior a 40 horas; o público-alvo, pois a maioria pediu que o curso fosse ofertado para os seus familiares também; o número de vagas ofertadas, pois, apesar da desistência de alguns agentes em função da indisponibilidade de horário compatível com o curso, outros agentes gostariam de ter participado, mas não puderam se inscrever com o curso já em andamento.

Após o término do curso e entrega dos certificados, foram realizadas duas atividades com os alunos extensionistas: uma palestra sobre inclusão digital, apresentando experiências de outros projetos realizados no Brasil e na Espanha; uma reunião para o compartilhamento das experiências adquiridas ao longo do projeto. Tais atividades tiveram a finalidade de aproximar os extensionistas da realidade que marca a inclusão digital e contribuir para a 
promoção de conhecimentos específicos adaptados à realidade do público-alvo do projeto, posto que eles também fazem parte da comunidade universitária.

Os extensionistas apontaram a percepção de melhorias no desempenho de todos os agentes terceirizados, em medidas diferentes, não apenas com base nos resultados quantitativos da pesquisa, mas a partir das ações que acompanharam ao longo das aulas e dos relatos dos participantes.

Por fim, a análise documental dos relatórios do curso permitiu verificar que apenas 1 participante teve presença integral no curso e 2 tiveram a frequência mínima ( $75 \%$ das aulas) para receber os certificados. Dos 4 participantes que desistiram do curso, 2 frequentaram parte das aulas, mas não atingiram a frequência mínima para o cumprimento do curso e recebimento do certificado.

\section{CONSIDERAÇÕES FINAIS}

A inclusão digital vem sendo tema de pesquisas com frequência cada vez maior, tendo como motivação capacitar parcelas excluídas social e digitalmente para o uso das informações, a partir das tecnologias digitais, como forma de promoção do seu desenvolvimento, reduzindo as desigualdades sociais. As políticas de inclusão digital devem ser formuladas a partir do estudo prévio dos contextos sociais e necessidades informacionais da comunidade, o que leva a refletir sobre o processo que irá nortear o acesso e uso das informações, bem como a mediação entre os usuários da informação e as tecnologias, contexto no qual se insere a Ciência da Informação.

Nesse cenário, esta pesquisa apresentou os resultados obtidos no projeto de extensão Inclusão digital de agentes terceirizados do campus IV da UFPB, desenvolvido em 2015. As ações do projeto foram planejadas e executadas com o intuito de contribuir para o desenvolvimento social e profissional do público-alvo, sendo identificadas, inicialmente, as suas maiores dificuldades e necessidades quanto ao acesso e uso do computador e da internet.

É perceptível que os conteúdos abordados dentro do tempo destinado para a execução do projeto não foram suficientes para atender a todas as necessidades dos participantes. Ainda assim, os resultados do projeto permitem inferir que os objetivos propostos foram atendidos, tanto em relação ao público-alvo, como aos alunos extensionistas, ressaltando-se que este foi 
apenas o primeiro passo para que se tenha, verdadeiramente, a inclusão digital com vistas à inclusão social, ao desenvolvimento pessoal e profissional do público-alvo.

\section{REFERÊNCIAS}

AGUILAR, Alejandra. Identidade/ diversidade cultural no ciberespaço: práticas informacionais e de inclusão digital nas comunidades indígenas no Brasil. Inf. \& Soc.:Est., João Pessoa, v. 22, n. 1, p. 121-128, jan./abr. 2012.

AUN, Marta Pinheiro (Coord.). Observatório da inclusão digital: descrição e avaliação dos indicadores adotados nos programas governamentais de infoinclusão. Belo Horizonte: Orion, 2007.

BATES, M. J. The invisible substrate of information Science. Journal of the American Society for Information Science, v. 50, n. 12, p. 1043-1050, 1999. Disponível em: $<$ http://onlinelibrary.wiley.com/store/10.1002/(SICI)1097-4571(1999)50:12\%3C1043::AIDASI1\%3E3.0.CO;2-/asset/1_ftp.pdf?v=1\&t=jb85e23e\&s=1791e265d7b9dc18e23e1f411ac 7ba3d7c5b88a9>. Acesso em: 09 set. 2016.

BOLZAN, Larissa Medianeira; VIEIRA, Kelmara Mendes; CORONEL, Daniel Arruda; LÖBLER, Mauri Leodir. Validação de um instrumento capaz de identificar o nível de inclusão digital individual. Inf. \& Soc.:Est., João Pessoa, v. 23, n. 2, p. 75-88, maio/ago. 2013.

BORKO, H. Information Science: what is it? American Documentation, v. 19, n. 1, p. 3-5, jan. 1968. Disponível em:

<https://www.marilia.unesp.br/Home/Instituicao/Docentes/EdbertoFerneda/k---artigo01.pdf>. Acesso em: 02 set. 2016.

CAPURRO, Rafael. Epistemologia e Ciência da Informação. In: Encontro Nacional de Pesquisa em Ciência da Informação, 5., 2003, Belo Horizonte. Anais. Belo Horizonte: Associação Nacional de Pesquisa e Pós-Graduação em Ciência da Informação e Biblioteconomia, 2003.

CIMADEVILA, Mely Paula Rabadan; ZUCHETI, Dinorá Tereza; BASSANI, Patrícia B. Scherer. O novo profissional da Rede Estadual do Rio Grande do Sul e as tecnologias na educação. ETD: Educ. temat. Digit. Campinas, SP. v.15 n.1 p.67-86 jan./abr. 2013.

FREIRE, Isa Maria. Reflexões sobre uma ética da informação na sociedade em rede. Ponto de Acesso. Salvador, v. 4, n. 3, p. 113-133, dez. 2010.

MARTINI, Renato. Inclusão digital e inclusão social. Revista IBICT, v. 1, n. 1 (2005). Disponível em: <http://revista.ibict.br/inclusao/index.php/inclusao/article/view/7/13>. Acesso em 20.08.2014. 
MASSENSINI, Rogério Luís. Inclusão digital: sob a ótica da cidadania plena.

DataGramaZero - Revista de Ciência da Informação, v. 12, n. 2, abr. 2011.

MEDEIROS NETO, Benedito; MIRANDA, Antônio. Aferindo a inclusão informacional dos usuários de Telecentros e laboratórios de escolas públicas em programas de inclusão digital brasileiros. Inf. \& Soc.:Est., João Pessoa, v. 19, n. 3, p. 109-122, set./dez. 2009.

PINHEIRO, Marta Macedo Kerr. Observatório da Inclusão Digital: descrição e avaliação dos indicadores adotados nos programas governamentais de infoinclusão. In: VIII Encontro Nacional de Pesquisa em Ciência da Informação (2007) Salvador/BA. Disponível em: $<$ http://enancib.ibict.br/index.php/enancib/viiienancib/paper/viewFile/2917/2044>. Acesso em 05.02.2015.

PINHO NETO, Júlio Afonso Sá de. A inclusão digital dos agentes de limpeza urbana e dos agentes ambientais da coleta seletiva de lixo da cidade de João Pessoa/PB. Inf. \& Soc.:Est., João Pessoa, v.22, p. 135-143, Número Especial, 2012.

Reflexão crítica sobre os Telecentros de informação e educação na cidade de João Pessoa. Inf. \& Soc.:Est., João Pessoa, v. 21, n. 3, p. 145-154, set./dez. 2011.

SARAIVA, Henrique; MARTINS, Paulo Emílio Matos; PIERANTI, Octávio Penna (Orgs). Democracia e regulação dos meios de comunicação de massa. Rio de Janeiro: Editora FGV, 2008.

SILVA, Helena; JAMBEIRO, Othon; LIMA, Jussara; BRANDÃO, Marco Antônio. Inclusão digital e educação para a competência informacional: uma questão de ética e cidadania. Ci. Inf., Brasília, v. 34, n. 1, p. 28-36, jan./abr. 2005.

VECHIATO, Fernando Luiz; VIDOTTI, Silvana Aparecida Borsetti Gregório. Contribuições de elementos do construtivismo e da mediação da informação para a inclusão digital de idosos. Inf. Inf., Londrina, v. 15, n. 2, p. 40 - 59, jul./dez. 2010. 